\title{
Gambling behavioural change during the Covid-19 pandemic: public health policies perspectives
}

\author{
Capriulo, A.P, Torri, A., Calloni, L., Parisi, G., De Pascalis, L., and Celata C. \\ Specific Prevention Division, Health Protection Agency - ATS Milano, Technical Staff Lombardy Region \\ * Correspondence: acapriulo@gmail.com
}

\begin{abstract}
Italy faced the covid-19 emergency through the so-called "mitigation" approach (Giarelli \& Vicarelli, 2020), having a significant impact on health conditions and people's behaviours, like gambling. Gambling is a growing phenomenon affecting about $36.4 \%$ of the Italian population with implications on social relations, economy and public health. Specifically, during the lockdown period, the access to Italian on-site game rooms was reduced (Prime Ministerial Decree of 8/3/20) by limiting game opportunities, except for online ones. This fact led to a change in gambling, highlighting the importance of both online gambling and the development of public prevention measures. The paper aims to study how environmental variables, such as Covid-19 containment measures, could affect gambling behaviour and whether this may have an impact on public policies. The study was carried out through a comparative analysis of scientific articles, regulations and statistical data about how gambling change during the Covid-19 pandemic. Unlike the international context, there are not neither scientific articles nor official data about the development of gambling behaviour during the lockdown in Italy yet, except for a research conducted by CNR's Institute of Clinical Physiology. Findings show just a little portion of onsite gamblers moved to online gambling offer. However, unofficial data about gambling consumption show opposite results, i.e. it occurred a significant onsite gambling reduction in favour of an increase of online activity. Furthermore, since June data show a growth in gambling behaviour, thus, together with online values, gambling consumption does not seem to be reduced in the first quarter of 2020. In conclusion, limited official data show gambling is a complex and widespread phenomenon embedded in Italy, which hasn't suffered a significant decrease despite all the changes occurred. Moreover, the pandemic highlighted the importance of online gambling, which needs to be more considered from public health policies.
\end{abstract}

Keywords: Covid-19; gambling; public health policies; online gambling; health emergency

\section{Introduction}

On the $11^{\text {th }}$ of March 2020, the World Health Organization stated to consider Sars$\mathrm{CoV}-2$ infection as a pandemic. Since then, the pandemic has been constantly monitored until today.

In a global scenario in which States' management responses to the emergency have been quite diverse, Italy carried out a so-called "mitigation" strategy (Giarelli \& Vicarelli, 2020). Given different and complex sets of cases and the difficulty to proceed quickly and rigorously, the mitigation strategy plan was to take action with specific prevention and protection measures, such as total lockdown and mandatory social distancing (DPCM 08/03/2020).

Since then, these measures have been defined and adapted many times: from their easing in the summertime, lockdown's measure has been newly introduced, albeit through diversified regional restrictions depending on each territory's risk conditions (DPCM 03/11/2020).

Among the activities subjected to these limitations, the analysis here presented concerns pathological gambling, which is a relevant risk factor for Italian public health. 
"Gambling disorder" has been formally recognized as a neuropsychobiological disease. It was listed under "Substance-related and addictive disorders" in the DSM-V, because it is characterized by all three components of the other addiction diseases: obsessivity, impulsivity, and compulsivity (APA, 2013). Gambling disorder can be considered a complex phenomenon, resulting in negative effects on the person's physical and mental health. Moreover, it also contributes developing economic, social, and legal problems (Dowling et al., 2015). Besides, these consequences can have an impact on the pathological gambler's family, on his relationships and, more generally, on the whole community (Bianchetti \& Croce, 2007; Shaw et al., 2015; Goodwin et al., 2017).

In Italy, especially in recent years, gambling is constantly increasing, both as consumption and expenditure behaviour but also for the risk to become an overuse and an addiction. The Istituto Superiore di Sanità (ISS) study, conducted from 2016 to 2019, showed that the $36,4 \%$ of the legally adult population (18.450.000) gambled at least once in the last 12 months; among these people, one and a half million showed a "problematic profile"1.

The availability and the variety of gambling's range facilitate the growth of the phenomenon, both onsite and online. The Agenzia delle Dogane e dei Monopoli (ADM), manages the gambling offer and its economic quantification. Moreover, the ADM guarantees the legality and the safety of gambling. the. In 2019, the gross gambling revenue was over 110 billion euros, with an increase of 3,2 billion compared to 2018 (ADM, 2020). At the same time, it's important to consider the onsite and online trend of gambling and its impact on overall data: over the past three years, in fact, online gambling increased compared to the onsite one $(+34,74 \%$ vs. $-6,38 \%)$.

Although its complexity and pervasiveness, the awareness of gambling-related harms is still scarce and there is low health literacy in the general population. Due to its legality and availability in everyday life contexts, it is considered a socially acceptable form of entertainment (Calado \& Griffiths, 2016).

Covid-19 pandemic, however, has changed gambling availability and its characteristics through some regulatory measures, which in Italy have been enacted both by national and regional governmental bodies and by the organs responsible of the legal gambling industry, such as ADM. These measures imposed the closure of the onsite gambling activities' to prevent customers' gathering and permanency inside.

The following figure (Figure 1) shows a view of the legislative provisions taken from Mars to November 2020 (Figure 1).

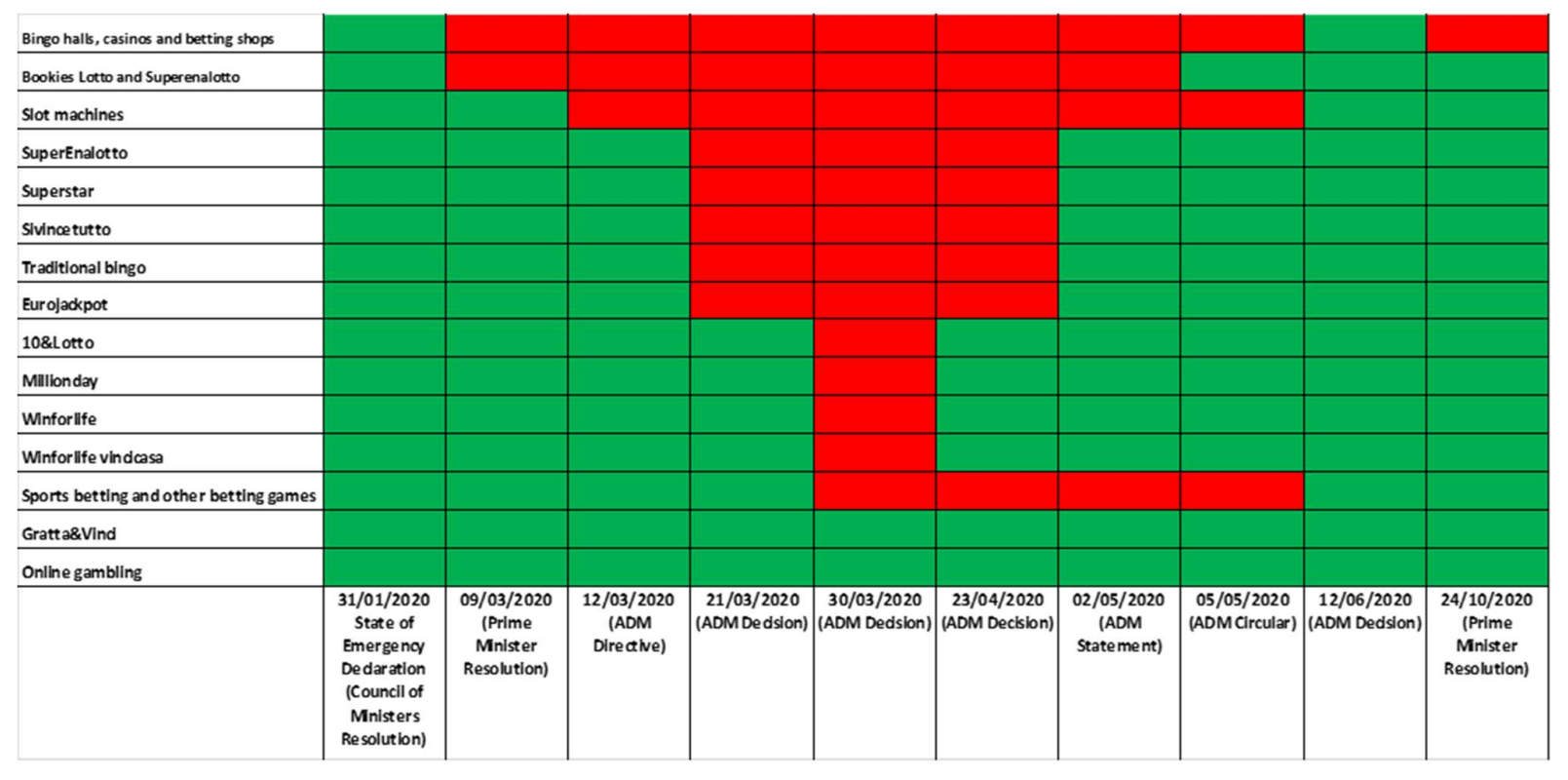

${ }^{1}$ http://www.salute.gov.it/portale/salute/p1 5.jsp?lingua=italiano\&id=60\&area=Disturbi psichici 
Figure 1. - Legislatives enacted until October 2020 related to Gambling.

\section{Objectives and Method}

Given what was said above, the aim of this contribution is to explore if and how the aspects of the context, as Covid-19 containment measures, have influenced gambling behavior and the potential impact in regard of public policy. A comparative analysis was conducted on national and international scientific articles, regulations and statistical data, official and otherwise, regarding the evolution of gambling behavior during the pandemic. Specifically, these evidences have been identified from studies available on the main scientific online databases (Google Scholar, Psycinfo, Pubmed, Scopus). The articles have been read and analyzed by two independent researchers.

\section{Results}

The analysis of international literature showed that in several States the offer of gambling was subjected to limitations also because of the restrictions to access to the places of game (Feuillet Syntèse 2020). Instead, generally only in a few cases, limits have been set regarding online gaming and digital entertainment consumption (Javed, 2020; Perez, 2020; Columb et al., 2020).

Considering the different measures taken by the different States during the period of emergency, the analysis of the international literature on the availability of the supply and on the consumption of gambling, shows heterogeneous results.

On the one hand, some studies regarding international experiences, show an increase of online gambling in general population (Brown, \& Hickman, 2020; Xuereb, Silas et al., 2020 ) and the population of pathological gamblers. In the latter case, this is also related to an increased risk of substance abuse (Price, 2020).

One the other hand, some research shows gambling did not attract new consumers in the lockdown period (Auer, Malischnig \& Griffiths, 2020). However, "frequent" gamblers continued taking advantage of the types of gambling remained available, testing also new games, increasing the duration of game consumption or of the financial expenses for gambling activity (UK Gambling Commission, 2020), in some cases related to an increase in alcohol abuse (Håkansson, 2020).

In general, the literature available on the incidence of gambling behaviours during the pandemic, shows an uneven framework linked to the different restrictive measures adopted by the different States.

Moreover, it should be considered that the data presented by the studies were mostly collected through online surveys on limited population samples. This shows that the results represent only a population with computer skills that are able to access the survey via the web. For this reason, the evidences cannot be generalized to the whole population.

Related to the Italian context, in November 2020, 4 months after the complete reopening of all gambling venues and about a month after the new closure of gaming halls, bingo and betting (DPCM of 24 October 2020), there seems to be no official data on the game's trend and players' behavior, nor articles of literature that can provide an overview of the phenomenon during that period.

From an analysis on the main research engines, a single survey was identified. This study was conducted by the Institute of Clinical Physiology of the National Research Council (CNR-IFC) in collaboration with the National Association of Italian Municipalities (ANCI) by certain Regions and other institutional entities. The aim was to investigate changes in gambling behavior through an ad hoc questionnaire, administered online to 3971 volunteers between April and May 2020.

The research has shown that gambling behaviors associated to on-site game, exhibited a decrease for $35.4 \%$, the total interruption for $22.8 \%$. However, $26.6 \%$ of the sample states they have not changed habits and $13,9 \%$ reports having increase physical gaming opportunities. Among those who kept the physical gambling, there is a clear predilection for games such as scratch cards, Superenalotto and Lotto. 
Regards the frequency of play, most of the sample reports going out of the house from one to three times a month to play, with an expense of 10 euros for the entire lockdown period. However, $2.6 \%$ of the sample said they had spent between 200 and 500 euros. Compared to online, $33.8 \%$ of the sample claims to have increased that mode of play, $28.8 \%$ not to have changed their habits and $11.3 \%$ to have started during isolation, preferring typologies such as Texas poker, virtual machine and online sportsbook. The frequency of play is higher than on-site gambling: $30.5 \%$ played one or more times a day, as many times a week, $39 \%$ from one to four times a month. The expense was certainly more substantial: $14.6 \%$ reported to have spent over 500 euros, $11 \%$ between 200 and 500 euros. Interestingly, among those who responded to the survey, $32.9 \%$ of "physical" players and $52 \%$ of online players have seen the job position change (https://www.cnr.it/it/notastampa/n-9513/il-gioco-d-azzardo-al-tempo-del-covid-19). Finally, it should be noted that this survey has clear limitations with respect to the constitution of the sample (on a voluntary basis) and the online administration mode.

Similarly, there is low data availability about gambling consumption: official publication by ADM have not yet been released. AGIMEG, News Agency on the Gambling Market, however, has collected data on the progress of the game from the beginning of the emergency. This has made possible to highlight that, during the month of March, the period most affected by the restrictions, there has been an increase of $80 \%$ compared to last year on several types of online gambling (online poker, tournament and cash mode, online casino), with an extra income of 35 million euros.

In addition to these data, the agency has monitored the phenomenon during the epidemic period by type of game, highlighting how for the month of June, characterized by a progressive reduction of restrictions:

- Spending on online tournament poker had an increase of $54.2 \%$ compared to the same month last year, for a total of 8.4 million euros. Such increment is inferior compared to the increment of the first semester 2020 ( $+76.7 \%$ compared to last year).

- The spending on poker in attendance was 5.9 million euros, $35.6 \%$ more compared to last year. Also in this case, this increase is lower than the increase occurred in the first half of $2020(+52.2 \%$ compared to last year).

- The costs for the online casino in June was 98.6 million euros with an increase of $57.8 \%$ from the previous year, but less than the over 105 million recorded in May. In the first six months of 2020 , the online casino registered an increase of $37.1 \%$ compared to the first half of 2019.

It follows that the game of poker, after an increase during the lockdown, is similarly returning to the levels prior to the restrictions, while the online casino industry has remained stable (https://www.agimeg.it/giochionline/gioco-online-dati-semestre-2020poker-cash-tor-neo-e-casino).

The monitoring of data on horse-race and sports betting showed a decrease of $44.5 \%$ between March and June, from 620 million euros in the first half of 2019 to 344 million in 2020. Specifically, sports betting, due to the closure of gambling points (shops, tobacconists, etc.) and the restrictions imposed, has been reduced by $41.1 \%$. The same happened to on-site horse-race betting, which showed a decrease of $58.3 \%$. Virtual bets went from 13.2 million spending in the first half of 2019 to 33.5 million in the same half of 2020 (+152.7\%; https://www.agimeg.it/scommessesportive/crollo-scommesse-in-agenzia-conlockdown-nel-primo-semestre-2020-spesa-in-calo-del-445-online-cresce-del-26-addiobetting-exchange).

Interestingly, the gaming agency (AGIMEG) has highlighted a significant recovery in the gambling market since July. This is mainly due to the resumption of physical play and to the restart of the football championships, which aimed mitigating, along with online gambling, the effect of the restrictions. In fact, in the first eight months of the year the online market grew by $23 \%$. Moreover, the data for the month of October highlighted that the first 10 months of 2020 showed a spending in sports betting of 1.29 billion euros, 
increasing by $3.2 \%$ compared to 2019 (https://www.agimeg.it/scommessesportive/scommesse-sportive-fisico-online-nuovo-lockdown-compromera-ripresa-settore10-mesi-2020-segnare-32-grazie-work-titolari-agenzietraino-online-ecco-numeri).

\section{Discussion and Conclusions}

Two considerations developed from the above results which are essential for the implementation and planning of gambling prevention programs.

First of all, the analysis of both published data and scientific articles showed. Unlike other countries, a lack of research related to the Italian situation. In particular, these data would be useful to analyze and monitor all the changes occurred due to Covid-19 pandemic. Therefore, the lack of up-to-date data may limit the development of effective and prompt interventions.

On the other hand, despite we are still waiting for the official ADM's official information, data published by CNR-IFC and AGIMEG show an increase in online gaming market. In fact, this, combined with the resumption of sport championships starting from July 2020, have contributed to limit the losses of the gambling market due to Covid-19 restrictions. This finding seem to be quite consistent with one of the scenarios hypothesized by Mauro Croce, one of the leading Italian experts in the field. At the beginning of the lockdown, in fact, he assumed that, due to Covid-19 restrictions, the online gambling market would have been used by people who usually played on site as well. Therefore, the fact that gambling has not suffered significant losses, despite the restrictions in force during the lockdown period, highlights how and to what extent gambling is a rooted phenomenon within the Italian context.

Looking at these considerations it is necessary to rethink an analysis of gambling behaviour which can be helpful for political actions tackling Covid-19's consequences on one hand and public policies against gambling on the other. In fact, the programmatic aspect related to contrast and prevention of gambling addiction needs to take into account a whole series of factors in order to ensure its effectiveness, such as the intersectoral implications of gambling, the complexity of the phenomena and the changes in all the different sectors involved. For this reason, a comprehensive prevention action, able to go beyond the boundaries of the health sector, should be developed.

There is, therefore, a need to implement well-time research with representative samples that could be able to investigate changes in gambling context and behaviour, in order to read the phenomenon and provide tools for a previsional lecture of the related behaviours. In addition, it appears necessary to develop flexible forms of measures, strategies and political infrastructures, able to meet the needs emerging from data and researches.

The results of this study highlight the importance to dwell on both the online gambling phenomenon, which should be included in the official future planning documents, and the changes in supply and gaming behaviours due to Covid-19 gambling restrictions. In particular, on the basis of the Italian economic condition after Covid-19 pandemic, this latter subject has become more important. The pandemic generated some negative consequences for the Italian economy, such as a drop in the average turnover, the increase of redundancy fund and the average decrease in consumption. Scientific evidence shows how financial crisis can generate an increase in gambling (Economou et al., 2019; Håkansson, 2020) which becomes more attractive (Bianchetti \& Croce, 2007) and starts to be considered a shelter from everyday problems (Binde, 2009; Pedroni, 2016).

For all these reasons, gambling addiction represent a serious public health problem that requires cross-sectoral and multidisciplinary policies and the development of specific diagnosis, treatment and rehabilitation services (Canale et al., 2016; Pacifici et al., 2018). Monitoring both the phenomenon and game trends will lead the possibility of develop prompt and effective prevention and treatment programs as well as interventions that take into account the characteristics of all the players (target, age, gambling habits, etc.).

\section{References}

1. Agenzia delle Dogane e dei Monopoli (2020). Libro Blu 2019. 
2. Agenzia delle Dogane e dei Monopoli (2020). Direttiva Nº326 del 12/03/2020

3. Agenzia delle Dogane e dei Monopoli (2020). Determinazione Direttoriale $N^{\circ} 96788$ del 21/03/2020

4. Agenzia delle Dogane e dei Monopoli (2020). Determinazione Direttoriale $\mathrm{N}^{\circ} 102340$ del 30/03/2020

5. Agenzia delle Dogane e dei Monopoli (2020). Determinazione Direttoriale $N^{\circ} 125127$ del 23/04/2020

6. Agenzia delle Dogane e dei Monopoli (2020). Comunicato stampa del 02/05/2020

7. Agenzia delle Dogane e dei Monopoli (2020). Circolare $N^{\circ} 133309$ del 05/05/2020

8. Agenzia delle Dogane e dei Monopoli (2020). Determinazione Direttoriale $N^{\circ} 180229$ del 12/06/2020

9. American Psychiatric Association. (2013). Diagnostic and statistical manual of mental disorders (5th ed.). https://doi.org/10.1176/appi.books.9780890425596

10. Bianchetti, R. \& Croce, M. (2007). Il crescente mercato del gioco d'azzardo in Italia: violenza nascosta o indifferenza collettiva? Questioni sui costi sociali e sui... 'legittimi' guadagni. Sociologia del diritto, 2, Milano, Franco Angeli.

11. Binde, P. (2009). Exploring the impact of gambling advertising: An interview study of problem gamblers. International Journal of Mental Health and Addiction, 7(4), 541-554.

12. Calado, F., \& Griffiths, M. D. (2016). Problem gambling worldwide: An update and systematic review of empirical research (2000-2015). Journal of behavioral addictions, 5(4), 592-613. https://doi.org/10.1556/2006.5.2016.073

13. Canale, N., Vieno, A., \& Griffiths, M. D. (2016). The Extent and Distribution of Gambling-Related Harms and the Prevention Paradox in a British Population Survey. Journal of behavioral addictions, 5(2), 204-212. https://doi.org/10.1556/2006.5.2016.023

14. Columb, D., Wong, M. C., O'Mahony, V., Harrington, C., Griffiths, M. D., \& O'Gara, C. (2020). Gambling advertising during live televised male sporting events in Ireland: A descriptive study. Irish Journal of Psychological Medicine.

15. Dowling NA, Cowlishaw S, Jackson AC, Merkouris SS, Francis KL, Christensen DR. Prevalence of psychiatric co-morbidity in treatment-seeking problem gamblers: A systematic review and meta-analysis. Aust N Z J Psychiatry. 2015 Jun;49(6):519-39. doi: 10.1177/0004867415575774. Epub 2015 Mar 3. PMID: 25735959; PMCID: PMC4438101.

16. DCM 31/01/2020. Dichiarazione dello stato di emergenza in conseguenza del rischio sanitario connesso all'insorgenza di patologie derivanti da agenti virali trasmissibili.

17. DPCM 09/03/2020. Ulteriori disposizioni attuative del decreto-legge 23 febbraio 2020, n. 6, recante misure urgenti in materia di contenimento e gestione dell'emergenza epidemiologica da COVID-19, applicabili sull'intero territorio nazionale.

18. DPCM 24/10/2020. Ulteriori disposizioni attuative del decreto-legge 25 marzo 2020, n. 19.

19. DPCM 03/11/2020. Ulteriori disposizioni attuative del decreto-legge 25 marzo 2020, n. 19.

20. Economou, M., et al. (2019). Problem Gambling in Greece: Prevalence and Risk Factors During the Financial Crisis. Journal of Gambling Studies. 35. 10.1007/s10899-019-09843-2.

21. Giarelli, G., Vicarelli, G. (2020). Politiche e sistemi sanitari al tempo della pandemia da Covid-19:una lettura sociologica. Sociologia Italiana, 16, 69-86. DOI: 10.1485/2281-2652-202016-5

22. Goodwin, B.C., Browne, M., Rockloff, M., \& Rose, J. (2017). A typical problem gambler affects six others. International Gambling Studies, 17, 276-289. DOI: 10.1080/14459795.2017.1331252

23. Håkansson, A. Changes in Gambling Behavior during the COVID-19 Pandemic-A Web Survey Study in Sweden. Int. J. Environ. Res. Public Health 2020, 17, 4013.

24. Javed, J. (2020). eSports and gaming industry thriving as video games provide escape from reality during coronavirus pandemic. Retrieved from: https://www.wfaa.com/article/

25. Pacifici, R., Giuliani, M. \& La Sala, L. (2018). Disturbo da gioco d'azzardo: risultati di un progetto sperimentale. Rapporto Istituto Superiore di Sanità (IIS).

26. Shaw, M. C., Forbush, K. T., Schlinder, J., Rosenman, E., \& Black, D. W. (2007). The effect of pathological gambling on families, marriages, and children. CNS Spectrums, 12(8), 615-622. 